\title{
O SIGNIFICADO DA DOR FÍSICA NA PRÁTICA DO ESPORTE DE RENDIMENTO
}

\author{
MS. PETRUCIO VENCESLAU DE MOURA \\ Instituto de Educação Ciência e Tecnologia de Pernambuco, \\ Campus Barreiros (Barreiros - Pernambuco - Brasil) \\ Email: petrucio.moura@barreiros.ifpe.edu.br
}

\author{
MS. EMÍLIA AMÉLIA PINTO COSTA DA SILVA \\ Programa de Pós-graduação em Educação Física, Setor de \\ Ciências Biológicas, Universidade Federal do Paraná \\ (Curitiba - Paraná - Brasil) \\ Email:milapcosta@hotmail.com
}

\section{MS. PRISCILLA PINTO COSTA DA SILVA \\ Programa Associado de Pós-graduação em Educação Física, Universidade de Pernambuco/Universidade Federal da Paraíba Federal da Paraíba (Recife - Pernambuco - Brasil) Email: laprisci@gmail.com}

\section{DR ${ }^{\mathrm{a}}$. CLARA MARIA SILVESTRE MONTEIRO DE FREITAS \\ Escola Superior de Educação Física, Universidade de Pernambuco; \\ Programas Associados de Pós-graduação em Educação Física e em Enfermagem, Universidade de Pernambuco/Universidade Federal da Paraíba(Recife - Pernambuco - Brasil) \\ Email: clarasilvestre@uol.com.br}

\section{DR. IRAQUITAN DE OLIVEIRA CAMINHA}

Departamento de Educação Física e Programa de Pós-Graduação em Filosofia, Centro de Ciências da Saúde - Campus I, Universidade Federal da

Paraíba; Programa Associado de Pós-graduação em Educação Física,

Universidade Estadual de Pernambuco/Universidade Federal da Paraíba (João Pessoa - Paraíba - Brasil)

Email: iraqui@uol.com.br

\section{RESUMO}

Este estudo teve como objetivo compreender o significado referente à dor física presente na experiência vivida por mulheres atletas de rendimento. Para isso, cinquenta e duas atletas de

I. Apoio financeiro: Este estudo teve financiamento da Coordenação de Aperfeiçoamento de Pessoal de Nível Superior - Capes, no formato de bolsa de mestrado Reuni. 
futsal, basquete e voleibol, relataram suas percepções referentes às experiências de dor, por intermédio da aplicação das técnicas de entrevista e questionário. Os dados obtidos foram analisados mediante aplicação da estatística descritiva e Análise de Conteúdo de Bardin. Desta forma, a dor foi apresentada pelos sujeitos como parâmetro para a origem de experiências prazerosas na prática esportiva, como resposta natural do corpo ao treinamento, que permite a identificação do alcance máximo de esforço, e também como um agente limitador e incapacitante, principalmente durante a competição.

PALAVRAS-CHAVE: Dor; esporte; atletas; mulheres.

\section{INTRODUÇÃO}

A dor tem a função fisiológica de proteger a integridade corporal comprometida por ação mecânica, térmica ou química, por isquemia da região atingida ou processo inflamatório. Portanto, ela é o sinal corporal para a ocorrência ou iminência de lesões, chegando a ser considerada pelos sujeitos como a própria lesão (GUYTON; HALL, 2006; ORGANIZAÇÃO, 2003; SAKATA; ISSY, 2008; VAN WILGEN; VERHAGEN, 20I2).

No entanto, para compreender a experiência dolorosa, é necessário superar a perspectiva estritamente fisiológica e considerar que ela está atrelada ao contexto biopsicossocial, e expressa não apenas o desequilíbrio físico, mas também psíquico, pois a sua origem também se dá mesmo sem que haja lesão ou perigo para a estrutura física (NASIO, 2008; VAN WILGEN; VERHAGEN, 20 I2).

Sob o ponto de vista das relações sociais, surge a necessidade de expressar à coletividade a sua existência. Entende-se que a cultura influencia tanto na forma como o sujeito percebe e responde à experiência dolorosa, quanto na maneira de expressá-la. Neste sentido, cada cultura ou grupo social possui uma maneira própria de reagir e comunicar seu sofrimento. Portanto, a confirmação da existência da dor se dá para o outro por intermédio da comunicação, verbal ou não verbal, sendo a última identificada em decorrência de alterações nas expressões faciais, na conduta ou na dificuldade de realizar atividades (BUDÓ et al., 2007). Neste contexto, a dor tem como consequência sensações e reações distintas, a depender do sujeito e do momento vivido por ele. Portanto, o estado emocional, a experiência, a atenção e o humor podem modular o limiar de sensação e a experiência da dor vivida (BUSSONE, 2012; DEUS, 2009).

Na mesma perspectiva, Shilling e Mellor (20 I0) afirmam que a cultura ocidental tem por característica a intensa sensibilidade e aversão à dor. Ao considerar a construção da identidade de gênero, as mulheres são culturalmente apresentadas como mais resistentes à dor, enquanto os homens são considerados mais resistentes em expressar a experiência dolorosa (HORTENSE; ZAMBRANO; SOUSA, 2008). 
No entanto, Helman (2009) considera que a demonstração da capacidade de suportar a dor é geralmente associada à masculinidade, o que gera a necessidade de controlar as reações como um elemento formador das relações sociais.

Pode-se admitir que a transmissão dos códigos comportamentais relativos à experiência dolorosa inicia na infância, pois o bebê que tem fome, a comunica por meio de um signo de dor, o choro, e logo recebe os cuidados da mãe (LE BRETON, 1999). Logo mais, a criança que merece punição, por vezes a recebe na forma de dor infligida pelo adulto, que a utiliza como mecanismo de demonstração de poder. Percebe-se que a dor pode representar uma ampla gama de significados incluídos na comunicação corporal, que são transferidos ao vocabulário dos indivíduos, como a metáfora da presença de dor atribuída ao sofrimento emocional (HELMAN, 2009). Assim, a dor também é compreendida como um componente da imagem corporal, pois altera e hiperestima as regiões corporais, transformando a maneira como o corpo se apresenta para o sujeito (SCHILDER, 1999).

Entretanto, os fatores socioambientais não são relevantes apenas na ocorrência da experiência dolorosa, mas também na origem de situações que promovem esta experiência. A prática de exercícios de alta intensidade no esporte de rendimento está relacionada ao acometimento de estresse e traumas corporais e psicológicos (WIESE-BJORNSTAL, 20 I 0). No contexto esportivo, a dor física pode suceder das lesões traumáticas ou não-traumáticas, sendo classificadas como torção, distensão, luxação, contusão, fadiga ou fratura, e que atingem músculos, ossos e articulações (PETERSON, 2002; SCHNEIDER et. al. 2006; VAN RENSBURG; NOLTE, 20 I I). Tais eventos ocorrem na participação de atletas, tanto nas sessões de treinamento quanto nas competições esportivas (VAN WILGEN; VERHAGEN, 20 I 2).

Mas a cultura normativa do esporte de rendimento define que $\mathrm{O}$ atleta deve ser resistente à dor e se manter atuando mesmo lesionado. (WIESE-BJORNSTAL, 20 I 0). Tal fato também foi verificado em estudo realizado nos Jogos Pan Americanos de 2007, no Rio de Janeiro, que identificou que aproximadamente 22, 1 \% da delegação de atletas brasileiros participaram da competição lesionados (LOPES et al. 2009). Por isso, atletas apresentam maior tolerância à dor do que não-atletas, como consequência da resistência física e psicológica (capacidade de enfrentamento) adquirida pela grande exposição ao esforço e a experiências dolorosas (TESARZ et al., 20। 2).

Percebe-se que estas experiências resguardam ao esporte de rendimento um interessante locus de investigação, dada a diversidade de componentes que interferem na forma como os sujeitos enfrentam a dor física. Neste contexto, compreende-se a dor como um componente vivido da imagem corporal, resultante do conflito entre as ações e intenções humanas. Desta maneira, este estudo se baseia na busca pela compreensão dos significados atribuídos à dor física vivida 
por mulheres atletas na prática do esporte de rendimento, e na exploração da experiência dolorosa ocorrida durante as sessões de treinamento e em competição.

\section{MATERIAL E MÉTODOS}

O presente estudo caracteriza-se como uma pesquisa qualitativa de campo, pois dá ênfase ao sujeito e à análise do fenômeno a partir do conteúdo interpretativo dos dados (THOMAS; NELSON, 2002; MINAYO, 2004). Mediante o crescimento acelerado da participação feminina nas ultimas décadas (WOLMAN, 2009) e as características culturais que permeiam a construção do gênero e suas reações frente à experiência dolorosa (HELMAN, 2009), foram considerados sujeitos da pesquisa, atletas do sexo feminino, integrantes das equipes finalistas dos campeonatos pernambucanos oficiais do ano de 2010 , na categoria adulto, com mais de cinco anos de experiência nas modalidades esportivas: futsal, basquete e voleibol. Foram excluídas da amostra as atletas que apresentavam estes critérios: não estar em plena capacidade de participar dos treinos e competições; não atuar na equipe por mais três meses anteriores à realização da pesquisa; responder menos de $80 \%$ do questionário aplicado. Considerando estes critérios, 52 atletas participaram do estudo.

Para atender aos objetivos propostos por este estudo, foram aplicados como instrumento de pesquisa, um questionário e um roteiro de entrevista semiestruturada permitindo caracterizar a experiência de dor física vivenciada pelas atletas e os significados que elas atribuíram a essa experiência. A entrevista semiestruturada foi aplicada em uma sub-amostra contendo seis atletas, escolhidos aleatoriamente, que afirmaram já ter sofrido lesão em sua experiência esportiva, sendo escolhidas duas atletas por modalidade esportiva estudada. Os instrumentos foram construídos especificamente para este estudo, considerando a especificidade da temática abordada. Estes foram cuidadosamente analisados quanto à clareza, objetividade e sequência lógica, por dois pesquisadores com formação em psicologia, sociologia, e com vasta experiência no trato com a pesquisa qualitativa em Educação Física. Os instrumentos também tiveram seu conteúdo e linguagem analisados por um treinador esportivo e uma atleta de rendimento antes de sua aplicação.

As atletas foram informadas a respeito da existência da pesquisa e seu objetivo, tomando conhecimento da importância e valor científico relacionados a sua realização. A coleta de dados se deu no local de ocorrência dos treinamentos, sendo resguardada a privacidade do discurso, tanto na aplicação dos questionários quanto da realização das entrevistas. Após analisadas as respostas obtidas nos questionários, as atletas selecionadas para a entrevista foram contatadas, sendo realizada a gravação de seu discurso mediante utilização de aparelho de reprodução e gravação de áudio em formato MP3. 
As respostas advindas dos questionários e entrevistas, que constituíram dados quantificáveis, foram apresentadas mediante estatística descritiva, para descrever as características relevantes ao estudo do fenômeno. Estes dados foram gerenciados mediante utilização do programa estatístico SPSS v 10.0. Na apreciação dos dados qualitativos foi aplicada a Análise de Conteúdo de Bardin (2000) por meio da técnica de análise temática. Para isso, as entrevistas foram transcritas na íntegra mediante a reprodução dos arquivos que continham as falas. As falas foram categorizadas em blocos temáticos que remeteram aos objetivos e variáveis envolvidos neste estudo. Para isso, foi utilizado o programa Analysis of qualitative data - AQUAD, que permitiu destacar as palavras-chave (micro-unidades) e identificar o contexto no qual discurso se origina (macro-unidades). A partir da organização destas unidades temáticas uma rede articulada de informações foi produzida, resultando na construção de diagramas representativos do discurso por intermédio do programa Godiagram Express 2.6.2.

No cumprimento das determinações da Resolução n 196/96 do Conselho Nacional de Saúde/MS (BRASIL, 2003), este projeto foi avaliado e aprovado pelo Comitê de Ética em Pesquisa da Universidade de Pernambuco UPE, sob o número de registro CAEE: 0034.0.097.00-1 I. Todas as participantes foram informadas a respeito dos objetivos da pesquisa, do sigilo de sua identidade referente às informações coletadas e assinaram o Termo de Consentimento Livre e Esclarecido.

\section{RESULTADOS E DISCUSSÃO}

Este estudo analisou a representação da dor física presente no ambiente esportivo, e as características referentes à dor sofrida por mulheres atletas de rendimento nas diferentes situações de treinamento e competição.

Participaram do estudo 52 atletas, com idade entre 18 e 42 anos, integrantes de equipes femininas de futsal, basquete e voleibol, com experiência na prática esportiva de 12,5 \pm 7,0 anos, que participam de 4,0 \pm 2,2 competições anuais, treinando por um período total de 9,9 $\pm 2,2$ meses por ano, com uma frequência semanal de 3,6 $\pm 1,3$ de sessões de treinamento com duas a três horas de duração. Todas as atletas haviam participado de competições a nível regional, 67,3\% participaram de competições nacionais e I5,4\% haviam participado de competições mundiais na categoria adulto.

Portanto, podemos considerá-las atletas de rendimento, pois participam de atividade esportiva sistemática e competitiva, orientada à busca pelo melhor desempenho e regulamentada pelo uso de regras e códigos específicos para cada modalidade, regidos por um órgão regional de controle e representante de instâncias nacionais e internacionais (AZEVEDO; GOMES FILHO, 20 I2; SILVA; RUBIO, 2003; TUBINO, 2005). 
Os resultados qualitativos obtidos foram identificados a partir da interpretação de diagramas gerados a partir da análise dos discursos das atletas. No diagrama a seguir (FIGURA I) é apresentada a caracterização dos significados atribuídos à dor física vivida pelos sujeitos da pesquisa.

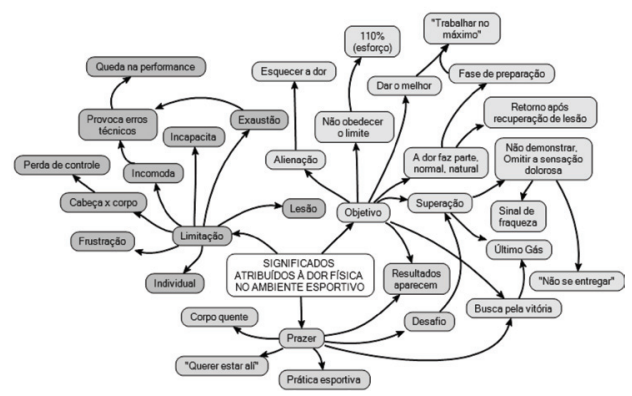

Figura I. Significados atribuídos à dor física no ambiente esportivo.

Com base nessa leitura, a fala das atletas destaca os elementos e características originados na interação entre o prazer de jogar e a superação da experiência dolorosa, definidos entre as categorias temáticas: Prazer; Objetivo e Limitação.

A partir do reconhecimento dos limites do corpo, claramente identificados em seu discurso pelas expressões "chegou ao limite"; "você tá na exaustão"; "você sente dor ao extremo", as atletas destacam a sensação de prazer como um importante agente na manutenção da prática esportiva: "o prazer daquele momento é muito superior à dor"; "dá uma sensação de prazer que você quer tá ali".

A esse respeito, Elias e Dunning (1992) afirmam não ser a vitória a única origem do prazer na prática esportiva, pois sua valorização se dá pela superação das dificuldades encontradas, dentre as quais, a dor também pode ser considerada. Nesta ótica, ela é compreendida como oposição ao prazer, mas ao mesmo tempo um componente determinante de sua origem. Tal afirmaç̧ão fica evidente nos trechos de discurso a seguir: "Num é que eu gosto de sentir a dor... eu gosto de treinar... Mas infelizmente o joelho vai doer mais." Diante do conflito apresentado nesta fala, a continuidade da atuação esportiva dependeria da capacidade de suportar a dor, o que confirma a abrangência dos significados atribuídos às sensações de dor ao aproximá-la ou distanciá-la da sensação de prazer.

A esse respeito, Le Breton ( 1999) afirma que a dor estabelece no sujeito certo distanciamento do mundo, pois considerando a estranheza da experiência sofrida, redireciona-o ao próprio íntimo e inibe a recepção de estímulos do ambiente. Contudo, o prazer agiria de maneira inversa expandindo a interação homem-ambiente. 
Segundo Merleau-Ponty (1994), a alteração dos significados naturalmente atribuídos às vivências de prazer e dor, presentes nesta pluralidade de interpretações, são originadas pelos processos cognitivos de associação de ideias, reflexo condicionado ou pela transferência de saberes e experiências.

No entanto, a simultaneidade da ocorrência da dor e do prazer gera representações perceptivas muito próximas, como pode ser observado a seguir: "Prazer? Sim. É você saber que aquilo que você tá fazendo [treinamento], tá dando resultado, pra você mesma"; "sente até um prazer que você quer tá ali jogando, mesmo com dor cê vai lá e termina”. Estas falas demonstram que a dor física na atividade esportiva pode ser considerada tanto um critério de avaliação da intensidade do treinamento, como elemento de valorização da vitória, ambas situações geradoras de prazer. Tal constatação põe em xeque a ideia de que a dor está unicamente associada ao sofrimento. Segundo Ross (20 I 2), a dor contida na experiência esportiva pode ser considerada pior do que em casos de tortura. No entanto, pode adquirir conotação positiva, tal qual nas mulheres durante o trabalho de parto. Por isso, a autora também afirma que as experiências prazerosas devem ser consideradas na definição de dor.

É possível afirmar que o prazer e a dor apresentam uma interação retroalimentada, na qual cada sensação estimula a presença da outra. Schilder (1999) analisa a interação entre a dor e a libido como componentes de estruturação da imagem do corpo, representada pelos impulsos sádicos, que estimulam a utilização da dor como ferramenta de dominação sobre um objeto de amor ou como mecanismo de teste de poder. Além disso, o autor refere-se ao masoquismo, que é o comportamento reservado àqueles que se identificam como objeto de amor e tornam-se sádicos consigo mesmo.

Quanto à relação entre a dor física e os objetivos intrínsecos à atividade esportiva, se destaca principalmente o alcance do nível máximo de esforço, como pode ser observado no trecho a seguir: "você sabe que tá dando o melhor"; "você sabe que essa dor faz parte"; "é ótimo sentir aquela dor, você sabe que tá fazendo a coisa certa"; "a dor é normal, é natural. Porque você tem que chegar lá"; "Você sentiu a dor, quer dizer que tá trabalhando no seu máximo”.

A tentativa de alcançar o máximo desempenho obriga o atleta a atuar sobre a linha tênue que difere a dor originada pela fadiga e a dor originada por lesão, como expressado no trecho de fala a seguir: "Eu achava que [a dor] era exaustão, então eu tinha que me condicionar". Sob a ótica desta atleta, o melhor condicionamento físico traria a diminuição da intensidade e da frequência de ocorrência da dor. No entanto, é perigoso acreditar que toda dor sofrida recai sob esta perspectiva, pois a mesma atleta afirmou que a dor mal compreendida naquele momento gerou uma lesão que a impediu de se manter na competição. 
Tal afirmação ganha reforço ao considerar que o desenvolvimento das capacidades de resistência cardiorrespiratória e muscular localizada amplia o período de atuação na atividade, retardando o aparecimento dos sinais de fadiga, dentre os quais a dor se inclui (BOMPA, 200 I). Portanto, a dor e sua função fisiológica de alertar o dano corporal às vezes são minimizadas e até mesmo negadas no ambiente esportivo. $\bigcirc$ fato de não considerar o risco à manutenção da integridade física do atleta amplia o dano já existente, ou causa falha na execução dos gestos técnicos, podendo gerar novas lesões (ADEDOYIN; JOHNSON, 20 I 2; PETERSON, 2002).

Por outro lado, quando a dor física supera as representações de prazer e sua interação com os objetivos contidos na atuação esportiva, surge a representação de limitação, causada principalmente pela incapacidade de manutenção da prática esportiva e o reconhecimento de novo rol de experiências e significados, destacados nos trechos dos discursos a seguir: "é a pior sensação que o atleta pode ter (...) é você errar uma bandeja, um arremesso porque seu punho já tá doendo, porque seu cotovelo já tá doendo, seu braço já tá doendo".

A dor e a lesão são, para o atleta, representantes da perda de sua identidade, pois por vezes, focam sua vida unicamente na prática esportiva, e a incapacidade de se manter nestas atividades ou a perda de seu papel na equipe pode abalá-lo emocionalmente (O'CONNELL, S.; MANSCHRECK, 20I2). Na mesma ótica, a dor física se aproxima à perspectiva de sofrimento emocional, como uma representação metafórica originada pela interrupção da prática esportiva ou pela queda de seu desempenho: "é a dor da frustração"; "chega no momento onde essa dor te incomoda, te incapacita de fazer as coisas".

Nasio (2008, p. I 6) afirma que devido ao intenso transtorno psíquico causado no momento da lesão, todo o corpo reage, é "todo o ser que se rompe, sofre e transforma-se em dor". No mesmo sentido, Le Breton (1999, p. I8) afirma que "a dor arranca o homem de si mesmo e o leva a enfrentar seus limites", e que o sofrimento causado não é relegado apenas ao corpo, mas ao indivíduo por inteiro.

Ampliando esta perspectiva, as atletas declaram que a percepção dos limites corporais possui componentes individuais e ambientais, sendo revelada a influência do instante vivido pelo sujeito, no qual se inscrevem as vivências passadas, como podem ser identificadas a seguir: "(...) você é humano num é... num é máquina. Então você fica limitado em alguns movimentos. Eu acho que é normal."; "eu acho que vai de cada pessoa, de cada motivação, de cada tipo de treinamento, de jogo (...) cabe a você ou não obedecer esse limite"; Então é a dor que limita, termina o seu desempenho"; "Quando você se machuca...Querendo ou não você tem limites."; "(...) você tem condições de fazer e num está conseguindo por causa da dor. Então é preferível você se afastar pra que essa lesão não piore, num chegue a te afastar... tipo é... permanentemente". 
Sabe-se que a dor altera a percepção ao sobrecarregar o modelo postural do sujeito, ativando um componente narcisista, que gera no corpo a função de elemento central da libido, a autoproteção. Isto ocorre porque a região dolorida se torna hiperestimada, alterando a capacidade de atenção (seleção dos estímulos sensíveis) e prontidão, influenciando negativamente a qualidade das ações e dos gestos. Na ótica do sujeito, a dor indica uma sensação antagônica à normalidade orgânica, que altera e reconstrói a representação dinâmica da imagem corporal (SCHILDER, 1999). Tais afirmações esclarecem que a queda do rendimento esportivo causada pela experiência dolorosa não se dá apenas por interferência na dimensão física, mas também cognitiva.

Para aprofundar a compreensão da dor, como um fenômeno vivido pelas atletas, se faz necessário considerar em que momentos da prática esportiva ela aparece, e a partir disso investigar a pluralidade dos significados e reações.

A dor originada durante a ocorrência de lesão resulta de substâncias químicas liberadas devido ao dano nos tecidos (ADEDOYIN; JOHNSON, 20 I2). Para os treinadores, a lesão é um evento negativo com consequências debilitantes (WADEY et al., 20 I3). No entanto, a maneira pela qual o sujeito reage à experiência dolorosa depende do significado atribuído à mesma no momento em que o atinge (LE BRETON, 1999).

Neste sentido, as sessões de treinamento foram referenciadas por $88,5 \%$ das atletas como o principal momento de ocorrência de dor física, enquanto a competição foi apontada por 53,5\% do grupo. A análise do discurso das atletas permitiu identificar a presença de características distintas da experiência da dor física nos momentos de competição e treinamento (FIGURA 2).

Dentre os elementos relacionados à lesão esportiva durante o treinamento, a compreensão das potencialidades e limites do corpo, aliada à liberdade de interromper as atividades, são identificadas como características específicas desta prática e que permitem prevenir lesões, como apresentado a seguir: "(...) em treinamento você fica mais relaxada (...) mas quando é em jogo, em competição, eu acho que você esquece a dor."; "(...) se sente uma dor no treino, você pára, é diferente, né. Lógico que não é qualquer dorzinha que faz o atleta parar um treinamento."; "(...) você pára, você se dá ao direito de sentir aquela dor e de tentar analisar o seu corpo e ver o que é que tá acontecendo".

Neste contexto, a função de sinal fisiológico e de componente de reconhecimento do corpo é ressaltada, pois é no treinamento que as capacidades físicas são reformuladas, com o objetivo de moldar os gestos técnicos ampliando seus efeitos na dinâmica das ações táticas e coletivas (BARBANTI, 2005). Algumas medidas devem ser tomadas para prevenir a ocorrência de dor e lesões em seus atletas, como incluir sessões de alongamento e exercícios de preparação para o 
treinamento, usar equipamento de proteção, atentar à adequação da superfície de jogo, realizar um programa de treino adequado às necessidades e capacidades individuais dos atletas, avaliar e corrigir a postura durante os movimentos técnicos (VAN RENSBURG; NOLTE, 20 I I).

Quanto ao contexto da competição esportiva, a dor da lesão superada pela motivação e o prazer de jogar refere-se ao desejo de buscar a vitória e auxiliar a equipe. Portanto, na perspectiva destas atletas, a dor deve ser omitida: "E eu tive a ruptura do [ligamento] esquerdo durante o jogo e eu num queria sair. Era decisão, era tudo, era o momento de brilhar. Era o momento de fazer a diferença, de ajudar o time"; "(...) eu acho que em jogo você esquece dor."; "(...) a gente sente a dor, mas a gente num quer mostrar pra ninguém que a gente sente dor. Porque eu num quero ver que as pessoas me achem fraca, né... eu num quero perder oportunidade"; "(...) quando tá no jogo, você não quer saber da dor. Você num quer saber se tá doendo seu dedo, se tá doendo sua cabeça. Você esquece a dor (...)".

Destacam-se nestes trechos, a interferência social e o contexto de situações que caracterizam a experiência vivida pelos sujeitos, apresentando componentes essenciais na interação entre o sujeito e a equipe, bem como na compreensão de que as suas expressões, atitudes e movimentos são constantemente avaliados, e podem expor a sua dor. Além disso, no ambiente competitivo, o atleta se vê na necessidade de defender os valores de garra e superação, de maneira a combater a demonstração de desgaste e sofrimento referente à dor física, que tendem a produzir marcas sociais relativas a estereótipos negativos (FREIRE; PEREIRA, 2009; SCHILDER, 1999).

Da mesma forma, Le Breton (1999) afirma que o sentimento de responsabilidade profissional tem participação no alívio da dor física. É nesta perspectiva que as atletas apontam restrições quanto à presença da dor física na competição, ou pelo menos a exposição de sua existência. Neste sentido, a intensidade da dor sofrida ganha em importância, pois o processo de transição da dor privada à dor pública sofre interferência do significado atribuído a esta. Mas se a dor é passível de ser suportada, deve permanecer no nível privado (HELMAN, 2009).

Dentre os fatores psicológicos que agem alterando a percepção dos sujeitos no decorrer da prática esportiva, a motivação reduz a percepção da dor, e a ansiedade age ampliando sua intensidade (DUBOIS; GALLAGHER; LIPPE, 2009). Outras variáveis psicossociais que podem influenciar na analgesia psiquicamente induzida são o efeito placebo ou a esperança de escapar dos riscos (HELMAN, 2009). Nesta mesma ótica, Dunn e Horgas (2004) adicionam aspectos como a negação, a distração ou a reinterpretação da experiência dolorosa como estratégias comportamentais de enfrentamento da dor. Acerca desta negação, Helman (2009) afirma que os soldados em situações de estresse extremo e ambientes de conflito têm sua atuação aproximada à situação de transe, na qual a dor não mais se apresenta. 
No entanto, as consequências dessa negligência à dor, caracterizada como alerta da ocorrência das lesões, promovem o desrespeito aos limites do corpo. Fato esse que é de conhecimento das atletas: "(...) você não admite sentir aquela dor. E aí é onde acontecem muitas lesões, porque você vai... você vai ao seu nível máximo, né."; "você esquece completamente a dor e volta pro jogo como se nada tivesse acontecido".

Tendo em vista os relatos apresentados, destacam-se afirmações preocupantes no que diz respeito à atuação do atleta nas atividades esportivas, mesmo estando lesionados ou com dor. O'Connell e Manschreck (20l2) afirmam que o suporte social dado por treinadores, companheiros de equipe e familiares podem induzir estas ações. Por vezes, os atletas não dão importância a lesões menores, realizando o tratamento inadequado ou por si mesmo, o que pode levar ao agravamento do dano físico (ADEDOYIN; JOHNSON, 20 I 2).

Percebe-se que neste conflito de reações corporais e desejos, não estão presentes apenas os aspectos físicos e emocionais momentâneos, mas também o produto de uma construção histórica, baseado no esforço dos treinamentos e nas dificuldades superadas anteriormente. Nesse sentido, Helman (2009) ratifica a atuação dos significados e sentidos da dor paralelamente às interferências do ambiente no qual a experiência vivida se insere, contribuindo na alteração da percepção da intensidade da dor.

Vale ressaltar que a integridade física dos atletas recai sob a responsabilidade do profissional de Educação Física, na função de treinador esportivo. Segundo o Conselho Federal de Educação Física, na ocorrência da lesão esportiva, o profissional de Educação Física deve atuar na solicitação do socorro especializado e na realização dos primeiros cuidados, até que se dê a chegada ou o acompanhamento do sujeito por profissionais especializados em primeiros socorros. No entanto, devem ser respeitadas as restrições referidas à sua área de atuação, que dizem respeito ao não uso de técnicas invasivas, prescrição ou uso de medicamentos. Nos casos que não envolvem risco de vida, estes profissionais devem atuar na utilização de compressas, na imobilização da área atingida, além de encaminhar o sujeito para avaliação médica (CONFEF, 20 I0).

Os profissionais de Educação Física devem estar atentos aos sinais de lesão que podem ser identificados em seus atletas, mesmo que estes não queiram demonstrar a existência de dor, são eles: inchaço, dificuldade de realizar ações, vermelhidão e aumento da temperatura da região lesionada (ADEDOYIN; JOHNSON, 20I2). Assim, deve ser considerada a importância do profissional de Educação Física no processo de conscientização dos atletas sobre o respeito aos limites do corpo e a compreensão de seus sinais, sem distinção entre os momentos de competição ou 
treinamento, pois a manutenção da integridade física dos sujeitos deve ser compreendida como uma vitória diária.

\section{CONCLUSÕES}

Este estudo analisou os significados referidos à experiência da dor física para atletas de rendimento. Considerando o discurso das atletas, a dor física apresentou aproximação com a sensação de prazer, nas situações em que esta é passível de ser superada, ou quando é considerada como uma resposta do corpo ao alcance máximo de exigência. Por outro lado, a dor física também foi considerada um elemento indispensável na busca dos objetivos do atleta, bem como um elemento limitador da prática esportiva, o que origina sofrimento e frustração nos sujeitos.

Também foi possível observar que os diferentes momentos vividos pelas atletas geram interpretações distintas da dor vivida no ambiente esportivo. Nessa perspectiva, a dor física vivenciada no momento do treinamento é compreendida, pelas atletas de rendimento, como a possibilidade de compreender os limites corporais e, na competição, como mais uma barreira a ser superada. Assim, dada a necessidade de contê-la, as atletas negam a dor sofrida, buscando a superação de seus limites, com objetivo de manter suas atividades.

Por fim, esta investigação nos permitiu compreender que o estudo da experiência dolorosa em atletas de rendimento vem contribuir na compreensão da construção do atleta, pois a estruturação da unidade de significados corporais originários das experiências dolorosas são determinantes na percepção do corpo e do ambiente no qual o sujeito está inserido.

\section{The Meaning of Physical Pain in Practice of Sport Performance}

ABSTRACT: This study aimed to understand the meanings related to physical pain present in lived experience of women athletes. Therefore, 52 women athletes of indoor soccer, basketball and volleyball reported their perceptions about the experience of pain through the use of questionnaires and interviews. Data was analyzed by descriptive statistics and content analysis of Bardin. The pain has presented as a parameter to the source of pleasurable experiences, it identified as a body's response to training, which allows identification the range of maximum effort, but also as an agent limiting and disabling of sports, especially during the competition. KEYWORDS: Pain; Sport; Athletes; Women.

\section{El significado del dolor físico en la práctica del rendimiento deportivo}

RESUMEN: Este estudio tuvo como objetivo comprender los significados relacionados con el dolor físico presente en la experiencia vivida de las mujeres atletas. Por lo tanto, el 52 atletas 
de fútbol sala, baloncesto y voleibol reportaron sus percepciones acerca de la experiencia del dolor, mediante el uso de cuestionarios y entrevistas. Los datos fueron analizados mediante estadística descriptiva y análisis de contenido de Bardin. El dolor se presenta como un parámetro para la fuente de experiencias placenteras, lo identificó como la respuesta del cuerpo a la formación, que permita identificar el rango de máximo esfuerzo, sino también como un agente limitante e incapacitante de los deportes, sobre todo durante la competición.

PALABRAS CLAVE: Dolor; deporte; atletas; mujeres.

\section{REFERÊNCIAS}

ADEDOYIN, R. A.; JOHNSON, E. O. Physical Management of Pain in Sport Injuries. In: ZASLAV, K. R. An international perspective on topics in sports medicine and sports injury. Rijeka: Intech, 2012. p. 403-4|4.

AZEVEDO, M. A. O.; GOMES FILHO, A. Competitividade e inclusão social por meio do esporte. Revista Brasileira de Ciências do Esporte, Florianópolis, v. 33, n. 3, p. 589-603, jul./set. 201 I.

BARBANTI, V. J. Formação de esportistas. Barueri: Manole, 2005.

BARDIN, L. Análise de conteúdo. Portugal: Edições 70, 2000.

BOMPA, T. O. A periodização no treinamento esportivo. São Paulo: Manole, 2001.

BRASIL. Ministério da Saúde. Conselho Nacional de Saúde. Resolução 196/96. Brasília, 2003.

BUDÓ, M. L. D. et al. A cultura permeando os sentimentos e as reações frente à dor. Revista da Escola de Enfermagem da USP, São Paulo, v.4I, n. I, mar. 2007.

BUSSONE, G. Pain, emotion, headache. Headache, St. Louis, v.52, n. 2, p. 98- I0 I, oct. 2012.

CONSELHO FEDERAL DE EDUCAÇÃO FÍSICA (CONFEF). Socorros de urgência em atividades físicas. Revista E. F., v. 8, n. 28, jun. 2008. Disponível em: <http://www.confef. org.br/extra/revistaef/arquivos/2008/N28_UNHO/I0_SOCORROS_DE_URGENCIA. PDF > Acesso em: 03 out. 2012

DEUS, J. Can we see pain? Reumatologia Clínica, Barcelona, v. 5, n. 5, p. 228-232, oct. 2009.

DUBOIS, D. Y.; GALLAGHER, R. M.; LIPPE, P. M. Pain medicine position paper. Pain Medicine, Glenview, v. 10, n. 6, p. 973-1000, sept. 2009.

DUNN, K. R.; HORGAS, A. L. Religious and nonreligious coping on older adults experiencing chronic pain. Pain Management Nursing, Philadelphia, v. 5, n. I, p. 19-28, mar. 2004.

ELIAS, N.; DUNNING, E. A busca da excitação. Lisboa: Difel, 1992.

FREIRE, V. M.; PEREIRA, M. E. Crenças estereotipadas acerca de atletas que sofreram lesões. Ciências \& Cognição, Rio de Janeiro, v. I4, n. 2, p. 225-234, jul. 2009. 
GUYTON, A. C.; HALL, J. E. Tratado de fisiologia médica. I I . ed. Rio de Janeiro: Elsevier, 2006.

HELMAN, C. G. Cultura, saúde e doença. 4. ed. Porto Alegre: Artmed, 2009.

HORTENSE, P.; ZAMBRANO E.; SOUZA F. A. E. F. Validação da escala de razão dos diferentes tipos de dor. Revista Latino-americana de Enfermagem, Ribeirão Preto, v. I6, n. 4, jul./ago. 2008.

LE BRETON, D. Antropología del dolor. Barcelona: Editorial Seix Barral, 1999.

LOPES, A. D. et al. Brazilian physiotherapy services in the 2007 Pan-American games: injuries, their anatomical location and hysiotherapeutic procedures. Physical Therapy in Sport, Edinburgh, v. 10, p. 67-70, may 2009.

MERLEAU-PONTY, M. Fenomenologia da percepção. São Paulo: Martins Fontes, 1994.

MINAYO, M. C. S. O desafio do conhecimento: pesquisa qualitativa em saúde. 8. ed. São Paulo: Hucitec, 2004.

NASIO, J. D. A dor física: uma teoria psicanalítica da dor corporal. Rio de Janeiro: Jorge Zahar, 2008.

O'CONNELL, S.; MANSCHRECK, T. C. Playing through the pain: psychiatry risks among athletes. Current Psychiatry, Philadelphia, v. II, n. 7, p. 16-20, july 2012

ORGANIZAÇÃO MUNDIAL DA SAÚDE (OMS). CIF: Classificação Internacional de Funcionalidade, Incapacidade e Saúde. São Paulo: EDUSP, 2003.

PETERSON, L. Lesões do esporte: prevenção e tratamento. 3. ed. Barueri: Manole, 2002.

ROSS, A. D. Revisiting the body in pain: the rhetoric of modern masochism. Sexuality \& Culture, New York, v. 16, n. 4, p. 230-240, sept. 2012.

SAKATA, R. K; ISSY, A. M. Guia de dor. 2. ed. Barueri: Manole, 2008.

SCHILDER, P. A imagem do corpo: as energias construtivas da psique. 3. ed. São Paulo: Martins Fontes, 1999.

SCHNEIDER, S. et al. Sports injuries: population based representative data onincidence, diagnosis, sequelae, and high risk groups. British Journal of Sports Medicine, Loughborough, v. 40. n. 4, p. 334-339, apr. 2006.

SHILLING, C.; MELLOR, P. A. Saver from pain or saved through pain? modernity, instrumentalization and the religious use of pain as a body technique. European Journal of Social Theory, Brighton, v.13, n. 4, p. 521-537, nov. 2010.

SILVA, M. L.; RUBIO, K. Superação no esporte: limites individuais ou sociais? Revista Portuguesa de Ciências do Desporto, v. 3, n. 3, p. 69-76, jul./dez. 2003.

TESARZ, J. et al. Pain perception in athletes compared to normally active controls: A systematic review with meta-analysis. Pain, Amsterdam, v. I 53, n. 6, p. I 253- I I 26, jun. 20 I 2. 
THOMAS, J. R; NELSON, J. K. Métodos de pesquisa em atividade fisica. 3. ed. Porto Alegre: Artmed, 2002.

TUBINO, M. J. G. Corpo, Educação Física e esporte. In: DANTAS, E. H. M. (Org.). Pensando o corpo e o movimento. 2. ed. Rio de Janeiro: Shape, 2005. p. 21 I-2 I7

VAN RENSBURG, D. C. J.; NOLTE, K. Sports injuries in adults: overview of clinical examination and management. South Africa Family Practice, Lyttelton Manor, v. 53, n. I, p. 2 I-27, jan./fev. 2011 .

VAN WILGEN, C. P.; VERHAGEN, E. A. L. M. A qualitative study on overuse injuries: The beliefs of athletes and coaches. Journal of Science and Medicine in Sport, Belconnen, v. I 5, n. 2, p. I16-121, mar. 2012.

WADEY, R. et al. Coaches' perceptions of athletes' stress-related growth following sport injury. Psychology of Sport and Exercise, Amsterdam, v. I4, n. 2, p. I25-135, mar. 2013.

WIESE-BJORNSTAL, D. M. Psychology and socioculture affect injury risk, response, and recovery in high-intensity athletes: a consensus statement. Scandinavian journal of medicine and science in sports, Copenhagen, v.20, suppl. 2, p. 103-1।1, oct. 2010.

WOLMAN, R. Knee injuries in femaly athletes. Rheumatology, Basel, v. 5, p. 527-528, oct. 2009

Recebido em: 8 ago. 2012

Aprovado em: I fev. 2013

Endereço para correspondência:

Petrucio Venceslau de Moura

Rua 189, n'165

Caetés I

Abreu e Lima-PE

CEP: 53530-474 